\title{
Intravitreal Dexamethasone Implant (Ozurdex) for Macular Edema Secondary to Retinal Vein Occlusion
}

\author{
Mustafa Deger Bilgec ${ }^{1}$, M.D., Nazmiye Erol ${ }^{2}$, M.D., Huseyin Gursoy ${ }^{3}$, M.D.*, Erdogan Yasar ${ }^{4}$, \\ M.D, Emre Tambova ${ }^{5}$, M.D., Ertugrul Colak ${ }^{6}$, Ph.D \\ ${ }^{1}$ Assistant Professor, Department of Ophthalmology, Eskisehir Osmangazi University Medical \\ Faculty \\ ${ }^{2}$ Professor, Department of Ophthalmology, Eskisehir Osmangazi University Medical Faculty \\ ${ }^{3}$ Associate Professor, Department of Ophthalmology, Eskisehir Osmangazi University Medical \\ Faculty \\ ${ }^{4}$ Medical Doctor, Department of Ophthalmology, Aksaray State Hospital \\ ${ }^{5}$ Medical Doctor, Department of Ophthalmology, Bilecik State Hospital \\ ${ }^{6}$ Associate Professor, Department of Biostatistics, Eskisehir Osmangazi University Medical Faculty \\ * Corresponding Author: Mustafa Deger Bilgec, Assistant Professor, Department of Ophthalmology, \\ Eskisehir Osmangazi University Medical Faculty
}

\begin{abstract}
Purpose: To evaluate the midterm efficacy of the dexamethasone implant injection in eyes with macular edema (ME) associated with retinal vein occlusion $(R V O)$.
\end{abstract}

Methods: Eyes with ME secondary to branch RVO (BRVO) or central RVO (CRVO) treated with an intravitreal dexamethasone implant were analyzed.

Results: In thirty-four eyes with BRVO, the median best-corrected-visual-acuity (BCVA) was improved from 0.70 at the baseline to $0.50 \log M A R$ at the final visit $(p<0.001$ ). In the CRVO group (ten eyes), the final $B C V A$ was not significantly improved.

In the BRVO group, the median CMT decreased from 449 at the baseline to 306 microns at the last visit ( $p<0.001)$. In the CRVO group, the median CMT increased from 503 at the baseline to 568 microns at the final visit. Twenty eyes with BRVO and seven eyes with CRVO received an additional injection. Laser therapy was applied in seven eyes with BRVO and three eyes with CRVO prior to the reinjection.

Conclusion: One or two intravitreal dexamethasone implant injections with or without laser therapy may be preferred in eyes with ME secondary to BRVO.

Keywords: branch retinal vein occlusion; central retinal vein occlusion; dexamethasone implant; macular edema; Ozurdex implant

\section{INTRODUCTION}

After diabetic retinopathy (DR), retinal vein occlusion (RVO) is the second most common cause of vision loss due to vascular diseases of the retina [1-3]. Branch retinal vein occlusion (BRVO) involving a single vein is the most common type (prevalence of $0.6 \%-1.1 \%$ ), whereas central retinal vein occlusion (CRVO) is less common (prevalence of $0.1 \%-0.4 \%$ ) [2, 4]. Macular edema (ME) is a common cause of vision loss in both BRVO and CRVO [5]. The pathogenesis of ME in RVO is not completely understood, but it may result from a variety of factors, including hydrostatic effects from increased venous pressure, the presence of inflammatory cytokines (e.g., prostaglandins and interleukin-6), the dysregulation of endothelial tight junction proteins [6], or increased amounts of vascular permeability factors, such as vascular endothelial growth factor (VEGF) [7].

Several therapies have been investigated for the treatment of ME associated with RVO. These include laser photocoagulation (8), the antiVEGF therapy (ranibizumab) [7, 9, 10], bevacizumab [11, 12], and aflibercept [12, 13] and the corticosteroids triamcinolone acetonide $[8,14,15]$ and dexamethasone [16]. Corticosteroids can help to reduce many of the processes thought to play a role in the development of ME in RVO [6, 17-20]. They 
have potent anti-inflammatory effects, can reduce vascular permeability, inhibit fibrin deposition and leukocyte movement, suppress homing and migration of inflammatory cells, stabilize endothelial cell tight junctions, and inhibit synthesis of VEGF, prostaglandins, and other cytokines [18]. Intravitreal injections of the lipophilic corticosteroid triamcinolone acetonide have been shown to produce benefits in eyes with RVO, but several adverse events have been noted (with elevated intraocular pressure [IOP] and cataract being the most common) $\quad[8,10,15, \quad 21-29]$. Other corticosteroids, however, have their own unique properties and may have different clinical profiles in intravitreal use [30].

Dexamethasone is a potent, water-soluble corticosteroid that can be delivered to the vitreous cavity using the dexamethasone intravitreal implant (DEX implant; Ozurdex, Allergan, Inc., Irvine, CA). The DEX implant is composed of a biodegradable copolymer of lactic acid and glycolic acid containing micronized dexamethasone. The drug copolymer complex gradually releases the total dose of dexamethasone over a series of months after it is inserted into the eye through a small pars plana puncture using a customized applicator system. In a recent study in eyes with persistent ME resulting from several different causes (including RVO), a 0.7-mg DEX implant produced improvements in visual acuity, macular thickness, and fluorescein leakage that were sustained for up to 6 months [16].

The purpose of the current study was to evaluate the midterm efficacy and safety of the DEX implant in eyes with vision loss due to ME associated with RVO.

\section{METHODS}

In this prospective, interventional study all participants provided their written informed consent. The study adhered to the principles of the Declaration of Helsinki. Patients with ME secondary to BRVO or non-ischemic CRVO who were treated with an intravitreal DEX implant were evaluated.

The inclusion criteria were as follows: the presence of ME following CRVO or BRVO with an onset within the previous 3 months; no previous therapy; a best-corrected visual acuity (BCVA) $\geq 20 / 400$ Snellen; a central macular thickness $(\mathrm{CMT}) \geq 250 \mu \mathrm{m}$ confirmed by spectral domain-optical coherence tomography
(SD-OCT -Cirrus HD-OCT model 5000; Carl Zeiss Meditec, Dublin, California, USA) and a follow-up of at least 12 months.

The main exclusion criteria included the following: clinically significant epiretinal membrane, vitrectomy prior to the injection, the presence of DR or diabetic ME, retinal or optic disc neovascularization, active or history of choroidal neovascularization, presence of rubeosis iridis, active infection, aphakia or anterior-chamber intraocular lens, clinically significant media opacity, glaucoma or current ocular hypertension requiring medication to control IOP in the study eye, or history of a steroid-induced IOP increase in either eye. Patients were also excluded if they had an uncontrolled systemic disease or were currently using or anticipated using systemic steroids or anticoagulants during the study.

Follow-up visits were performed at 1, 3, 6, 9 and 12 months after injection of the DEX implant. IOP was measured with Goldmann applanation tonometry, and CMT was measured with SD-OCT. The main outcome measures were BCVA, CMT and IOP. CMT was defined as the distance between the inner retinal boundary (internal limiting membrane) and outer retinal boundary (outer border of the photoreceptors) in the foveal area.

\section{Intravitreal Dexamethasone Implant Injection}

All intravitreal injections were performed in the operating room under sterile conditions. The eye was anaesthetized with topical anesthetics, and preoperative antisepsis was performed according to standard clinical practice. Next, 0.7 $\mathrm{mg}$ of dexamethasone was injected intravitreally through the pars plana using a 22-gauge applicator. Retreatment was based on an open pro re nata (PRN) regime (significant decline in the BCVA, as demonstrated by a loss of at least one line, or an increased CMT of 150 microns was noticed) [31]. Additionally, some patients received complementary sectoral or panretinal photocoagulation to ischemic areas according to the individual retinal perfusion status and the retinal angiography at the 6-month follow-up visit.

\section{Retreatment}

A significantly decreased BCVA and recurrent ME were noticed in twenty-one of thirty-four eyes with BRVO during the follow-up period. 
Early retreatment prior to the labeled 6-month interval was supported by the covering insurance company of the affected patient in twenty-one eyes of thirty-four initially treated eyes $(61.7 \%)$. A loss of 5 letters (4 eyes) and recurrent CME (17 eyes) were noticed in 21 of 34 eyes. Of these, one eye $(4.76 \%)$ received an anti-VEGF injection and $20(95.24 \%)$ received a second intravitreal DEX implant according to the physician's discretion. Seven eyes (20.58\%) received a sectoral laser photocoagulation prior to the second implant injection.

In the CRVO group, a significantly decreased BCVA and recurrent ME were noticed in seven of ten eyes during the follow-up period. Early retreatment was covered by the insurance company or preferred by affected patients in seven of ten initially treated eyes (70\%). A loss of 5 letters ( 0 eyes) and recurrent CME ( 7 eyes) were noticed in 7 of 10 eyes with CRVO during the follow-up period. These seven eyes (100\%) were treated with a second intravitreal Ozurdex injection based on the physician's discretion. Three eyes $(30 \%)$ received a panretinal laser photocoagulation due to retinal ischemia prior to the second implant injection.

\section{Statistics}

Changes between CMT values (as a continuous variable) obtained in clinical visual testing at each time-point were analyzed using paired ttests, and the changes between visual acuity values (as a discrete variable) at the same timepoints were analyzed using Friedman's two-way analysis of variance by ranks. The extent to which the disease duration prior to the initial Ozurdex injection affected the study outcomes was analyzed using a repeated-measures analysis of variance (ANOVA). Differences in the patients' characteristics at baseline (regarding age, BCVA and CMT) were assessed using an unpaired t-test. Statistical analyses were performed using IBM SPSS Statistics version 21.0. P-values $<0.05$ were required for statistical significance.

\section{RESULTS}

Forty-four patients with ME secondary to BRVO $(n=34)$ or CRVO $(n=10)$ who were treated with intravitreal DEX implant were included in the study. The patient characteristics are shown in Table 1.

Table1. Patients characteristics at baseline prior to the first intravitreal injeciton of $0.7 \mathrm{mg}$ dexamethasone implant. CRVO, Central Retinal Vein Occlusion; BRVO, Branch Retinal Vein Occlusion; SD, Standard Deviation; BCVA, best corrected visual acuity.

\begin{tabular}{|l|l|l|}
\hline \multicolumn{1}{|c|}{ Variable } & \multicolumn{1}{|c|}{ CRVO } & \multicolumn{1}{c|}{ BRVO } \\
\hline Number of patients & 10 & 34 \\
\hline Number of males & 7 & 14 \\
\hline Mean age (SD)(years) & $70.1 \pm 7.07$ & $62.4 \pm 7.73$ \\
\hline Median logMAR BCVA (SD) & $0.70(0.70-1.35)$ & $0.70(0.50-1.0)$ \\
\hline Mean central retinal thickness (SD), micron & $540 \pm 168(360-824)$ & $467 \pm 113(260-645)$ \\
\hline
\end{tabular}

The effects of the intravitreal dexamethasone therapy were analyzed separately for BRVO and CRVO.

In eyes with BRVO, treatment with an intravitreal DEX implant resulted in a significant improvement in the median BCVA $(\mathrm{p}<0.001)$, which decreased from $0.70 \log$ MAR at baseline to $0.50 \log$ MAR at 12 months after the implant. The median BCVA maintained was significantly better $(p<0.001)$ than the baseline BCVA at each follow-up visit.

Table2. The comparison of the best-corrected visual acuities (BCVA) in logMAR (logarithm of the minimum angle of resolution) in branch retinal vein occlusions at different visits using Friedman's Two-way Analysis of Variance by Ranks. The minimum and maximum values are given in parenthesis along with the means. The 25th and 75th percentile values are given in parentheses along with the medians. ${ }^{*} p<0.05$; MC = multiple comparisons.

\begin{tabular}{|c|c|c|c|c|}
\hline Visit time & Mean BCVA & Median BCVA & p value & Significant MC* \\
\hline Preinjection (0) & $0.80 \pm 0.41(0.22-1.80)$ & $0.70(0.50-1.0)$ & \multirow{6}{*}{$<0.001 *$} & \multirow{6}{*}{$\begin{array}{l}0 \text { vs } 1(\mathrm{p}<0.001) \\
0 \text { vs } 3(\mathrm{p}=0.004) \\
0 \text { vs } 6(\mathrm{p}=0.006) \\
0 \text { vs } 9(\mathrm{p}<0.001) \\
0 \text { vs } 12(\mathrm{p}=0.011)\end{array}$} \\
\hline At $1^{\mathrm{st}} \mathrm{m}(1)$ & $0.49 \pm 0.29(0.10-1.30)$ & $0.45(0.28-0.70)$ & & \\
\hline At $3^{\text {rd }} \mathrm{m}(3)$ & $0.53 \pm 0.31(0.10-1.50)$ & $0.45(0.36-0.70)$ & & \\
\hline At $6^{\text {th }} \mathrm{m}(6)$ & $0.55 \pm 0.37(0.10-1.50)$ & $0.50(0.30-0.70)$ & & \\
\hline At $9^{\text {th }} \mathrm{m}(9)$ & $0.54 \pm 0.35(0.10-1.30)$ & $0.50(0.22-0.78)$ & & \\
\hline At $12^{\text {th }} \mathrm{m}(12)$ & $0.60 \pm 0.38(0.10-1.50)$ & $0.50(0.30-1.00)$ & & \\
\hline
\end{tabular}




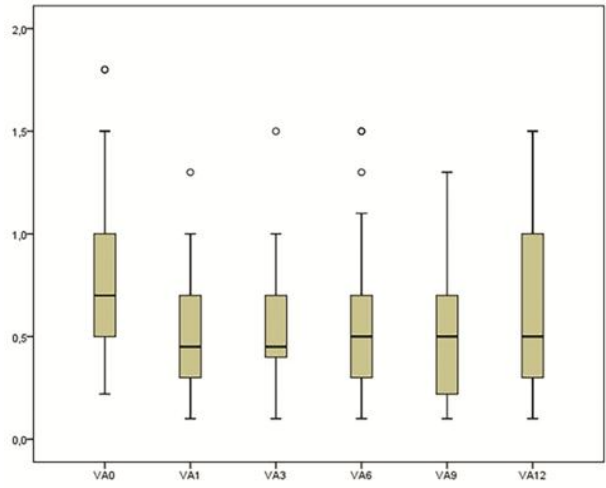

Figure1. The change in BCVA with the view box plot graphs at BRVO.

In eyes with CRVO, injection of an intravitreal DEX implant induced significant visual improvements of the median BCVA $(\mathrm{p}<0.009)$, from $0.70 \log \mathrm{MAR}$ at baseline to 0.50 and 0.70 $\log$ MAR at 3 and 6 months, respectively. The final median BCVA maintained was not significantly improved compared to the initial BCVA. Table 3 and Figure 2

Table3. The comparison of the best-corrected visual acuities (BCVA) in logMAR (logarithm of the minimum angle of resolution) in central retinal vein occlusions at different visits using Friedman's Two-way Analysis of Variance by Ranks. The minimum and maximum values are given in parenthesis along with the means. The 25th and 75th percentile values are given in parentheses along with the medians. ${ }^{*} p<0.05 ; \mathrm{MC}=$ multiple comparisons

\begin{tabular}{|l|l|l|l|l|}
\hline \multicolumn{1}{|c|}{ Visit time } & \multicolumn{1}{|c|}{ Mean BCVA } & Median BCVA & p value & Significant MC* \\
\hline Preinjection $(0)$ & $0.93 \pm 0.37(0.50-1.50)$ & $0.70(0.70-1.35)$ & & \\
\cline { 1 - 3 } At $1^{\text {st }} \mathrm{m}(1)$ & $0.74 \pm 0.40(0.22-1.50)$ & $0.65(0.40-1.03)$ & \multirow{3}{*}{$0.009 *$} & \multirow{2}{*}{0 vs $3(\mathrm{p}=0.042)$} \\
\cline { 1 - 3 } At $3^{\text {rd }} \mathrm{m}(3)$ & $0.67 \pm 0.38(0.10-1.50)$ & $0.50(0.50-0.93)$ & & 0 vs $6(\mathrm{p}=0.035)$ \\
\cline { 1 - 3 } At $6^{\text {th }} \mathrm{m}(6)$ & $0.70 \pm 0.41(0.05-1.50)$ & $0.70(0.45-1.00)$ & & \\
\hline At $9^{\text {th }} \mathrm{m}(9)$ & $1.00 \pm 0.80(0.30-0.48)$ & $0.85(0.48-1.20)$ & & \\
\hline At $12^{\text {th }} \mathrm{m}(12)$ & $0.84 \pm 0.39(0.40-1.50)$ & $0.85(0.48-1.15)$ & & \\
\hline
\end{tabular}

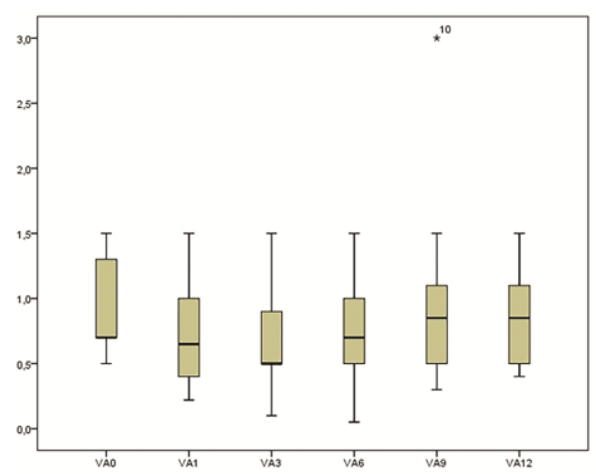

Figure2. The change in BCVA with the view box plot graphs at CRVO.

In eyes with ME secondary to BRVO, the median CMT decreased from 449 micron $(\mu \mathrm{m})$ at baseline to $306 \mu \mathrm{m}$ at 12 months. The median
CMT was significantly less than the baseline CMT at each follow-up visit $(\mathrm{p}<0.001)$.

Table4. The comparison of the central macular thickness (CMT) in branch retinal vein occlusions at different visits using Friedman's Two-way Analysis of Variance by Ranks. The minimum and maximum values are given in parenthesis along with the means. The 25th and 75th percentile values are given in parentheses along with the medians. ${ }^{*} p<0.05 ; M C=$ multiple comparisons.

\begin{tabular}{|c|c|c|c|c|}
\hline Visit time & Mean CMT $(\mu \mathrm{m})$ & Median CMT $(\mu \mathrm{m})$ & p value & \multirow{7}{*}{$\begin{array}{l}\text { Significant MC. } \\
0 \text { vs } 1(\mathrm{p}<0.001) \\
0 \text { vs } 3(\mathrm{p}<0.001) \\
0 \text { vs } 9(\mathrm{p}<0.001) \\
0 \text { vs } 12(\mathrm{p}<0.001) \\
1 \text { vs } 6(\mathrm{p}<0.001) \\
1 \text { vs } 12(\mathrm{p}=0.003) \\
3 \text { vs } 6(\mathrm{p}=0.010) \\
6 \text { vs } 9(\mathrm{p}=0.005)\end{array}$} \\
\hline Preinjection (0) & $467 \pm 113(260-645)$ & $449(373-569)$ & \multirow{6}{*}{$<0.001 *$} & \\
\hline At $1^{\mathrm{st}} \mathrm{m}(1)$ & $258 \pm 76(143-480)$ & $250(193-310)$ & & \\
\hline At $3^{\text {rd }} \mathrm{m}(3)$ & $277 \pm 74(168-449)$ & $267(222-314)$ & & \\
\hline At $6^{\text {th }} \mathrm{m}(6)$ & $392 \pm 124(188-694)$ & $373(297-475)$ & & \\
\hline At $9^{\text {th }} \mathrm{m}(9)$ & $308 \pm 121(189-617)$ & $253(226-351)$ & & \\
\hline At $12^{\text {th }} \mathrm{m}(12)$ & $358 \pm 142(204-652)$ & $306(234-485)$ & & \\
\hline
\end{tabular}




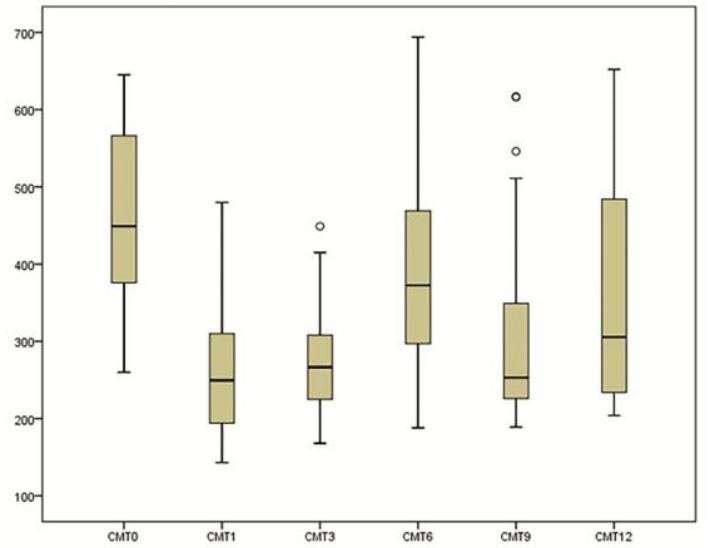

Figure3. The change in CMT with the view box plot graphs at BRVO.

In CRVO, the median CMT maintained was significantly reduced compared with the baseline at the first two follow-up visits $(\mathrm{p}<0.001)$. However, the median CMT increased from $503 \mu \mathrm{m}$ at the baseline to $568 \mu \mathrm{m}$ at 12 months.

Table5. The comparison of the central macular thickness (CMT) in central retinal vein occlusions at different visits using Friedman's Two-way Analysis of Variance by Ranks. The minimum and maximum values are given in parenthesis along with the means. The 25th and 75th percentile values are given in parentheses along with the medians. ${ }^{*} p<0.05 ; M C=$ multiple comparisons.

\begin{tabular}{|c|c|c|c|c|}
\hline Visit time & Mean CMT $(\mu \mathrm{m})$ & Median CMT ( $\mu \mathrm{m})$ & $p$ value & Significant MC* \\
\hline Preinjection (0) & $540 \pm 168(360-824)$ & $503(378-714)$ & \multirow{6}{*}{$<0.001 *$} & \multirow{6}{*}{$\begin{array}{l}0 \text { vs } 1(p<0.001) \\
0 \text { vs } 3(p=0.008) \\
1 \text { vs } 12(p=0.005)\end{array}$} \\
\hline At $1^{\mathrm{st}} \mathrm{m}(1)$ & $224 \pm 73(192-222)$ & $201(192-222)$ & & \\
\hline At $3^{\text {rd }} \mathrm{m}(3)$ & $311 \pm 230(156-902)$ & $212(195-350)$ & & \\
\hline At $6^{\text {th }} \mathrm{m}(6)$ & $421 \pm 175(204-725)$ & $394(265-571)$ & & \\
\hline At $9^{\text {th }} \mathrm{m}(9)$ & $355 \pm 150(186-659)$ & $313(240-463)$ & & \\
\hline At $12^{\text {th }} \mathrm{m}(12)$ & $496 \pm 218(226-780)$ & $568(242-691)$ & & \\
\hline
\end{tabular}

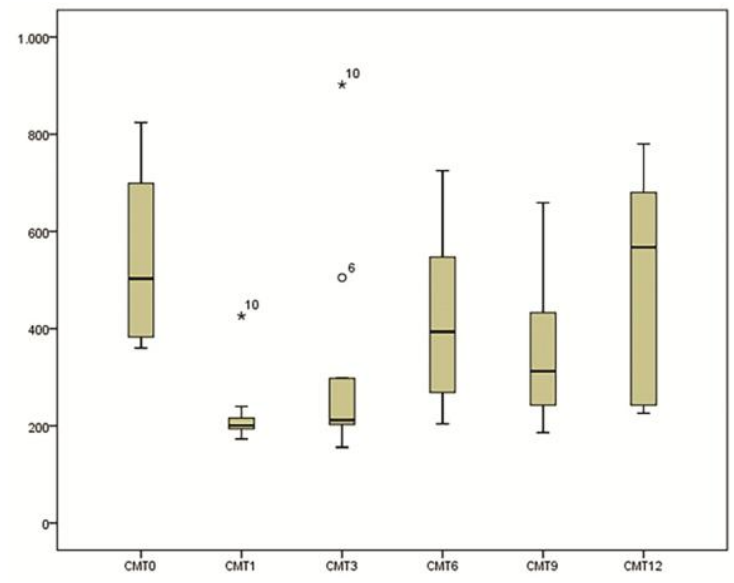

Figure4. The change in CMT with the view box plot graphs at CRVO.

No major ophthalmologic (retinal detachment, uveitis, endophthalmitis, retinal artery occlusion) or systemic (thromboembolic events, systemic hypertension, myocardial infarction) side effects occurred.

A high IOP over $21 \mathrm{mmHg}$ was noted in ten patients in the BRVO group (29.4\%) and in two patients in the CRVO group (20\%) during the 12 months of follow-up time. IOP elevation was controlled by medical therapy in all patients.
A statistically significant increase in IOP was observed at months 1,3 and 9 in the BRVO group compared to the baseline values. However, there was no significant difference in IOP at the 6th and 12th month compared to the initial values. There was no statistically significant change in the mean IOP in the CRVO group at any visit. The mean and median IOP changes are shown in the tables for the BRVO and CRVO groups. 
Table6. The comparison of the intraocular pressure (IOP) in branch retinal vein occlusions at different visits using Friedman's Two-way Analysis of Variance by Ranks. The minimum and maximum values are given in parenthesis along with the means. The 25th and 75th percentile values are given in parentheses along with the medians. $* p<0.05 ; M C=$ multiple comparisons.

\begin{tabular}{|c|c|c|c|c|}
\hline Visit time & Mean IOP (mmHg) & Median IOP (mmHg) & $P$ value & Significant MC* \\
\hline Preinjection (0) & $15 \pm 3(9-21)$ & $14(13-16)$ & \multirow{6}{*}{$<0.001 *$} & \multirow{6}{*}{$\begin{array}{l}0 \text { vs } 1(\mathrm{p}=0.005) \\
0 \text { vs } 3(\mathrm{p}=0.035) \\
1 \text { vs } 6(\mathrm{p}=0.004) \\
1 \text { vs } 12(\mathrm{p}=0.025) \\
3 \text { vs } 6(\mathrm{p}=0.031)\end{array}$} \\
\hline At $1^{\text {st }} \mathrm{m}(1)$ & $17 \pm 4(11-32)$ & $17(14-19)$ & & \\
\hline At $3^{\text {rd }} \mathrm{m}(3)$ & $17 \pm 5(9-36)$ & $16(14-19)$ & & \\
\hline At $6^{\text {th }} \mathrm{m}(6)$ & $15 \pm 2.6(9-20)$ & $15(13-16)$ & & \\
\hline At $9^{\text {th }} \mathrm{m}(9)$ & $17 \pm 5(11-38)$ & $16(14-18)$ & & \\
\hline At $12^{\text {th }} \mathrm{m}(12)$ & $15 \pm 2(10-22)$ & $15(13-16)$ & & \\
\hline
\end{tabular}

Table7. The comparison of the intraocular pressure (IOP) in central retinal vein occlusions at different visits using Friedman's Two-way Analysis of Variance by Ranks. The minimum and maximum values are given in parenthesis along with the means. The 25th and 75th percentile values are given in parentheses along with the medians.

\begin{tabular}{|l|l|l|c|}
\hline \multicolumn{1}{|c|}{ Visit time } & \multicolumn{1}{|c|}{ Mean IOP $(\mathbf{m m H g})$} & \multicolumn{1}{|c|}{ Median IOP $(\mathbf{m m H g})$} & p value \\
\hline Preinjection $(0)$ & $14 \pm 3(8-19)$ & $14(11-16)$ & $>0.05$ \\
\hline At $1^{\text {st }} \mathrm{m}(1)$ & $17 \pm 4(12-23)$ & $16(13-22)$ & \\
\hline At $3^{\text {rd }} \mathrm{m}(3)$ & $15 \pm 3(10-20)$ & $16(12-18)$ & \\
\hline At $6^{\text {th }} \mathrm{m}(6)$ & $14 \pm 3(8-18)$ & $14(13-15)$ & \\
\hline At $9^{\text {th }} \mathrm{m}(9)$ & $16 \pm 3(11-20)$ & $15(14-18)$ & \\
\hline At $12^{\text {th }} \mathrm{m}(12)$ & $17 \pm 8(10-38)$ & $14(13-18)$ & \\
\hline
\end{tabular}

During follow-up, cataracts were reported as adverse events in four of twenty-eight phakic eyes $(14.2 \%)$ in the BRVO group and one of seven phakic eyes $(14.2 \%)$ in the CRVO group. Five patients had a surgical procedure for cataract in the study eye (four eyes in the BRVO group and one eye in the CRVO group).

\section{DISCUSSION}

Ozurdex is the first drug approved for the treatment of ME in RVO that may offer patients a long-lasting relief from their visual symptoms and macular edema with a limited number of required follow-up visits $[32,33]$. In this study, we evaluated the effects of intravitreal Ozurdex treatments administered on a PRN regime for RVO. Overall, we found sustained functional (BCVA) and morphological (CMT) improvements in eyes with BRVO. We also obtained an improvement in CRVO cases in the initial visits, but the final outcomes were not different from the preinjection values. These findings support previous observations that CRVO is a more visually disabling disorder than BRVO [34, 35].

In the current study including thirty-four BRVO cases, the visual improvement was significant from the initial visits to the last visit. In $61.7 \%$ of our cases, an additional injection was required. The multicenter GENEVA trial was the first study to assess the clinical effects of
Ozurdex injections after its approval in a clinical routine setting [36]. The trial examined eyes with ME after an intravitreal Ozurdex injection on a monthly basis. Treatment with intravitreal dexamethasone injections led to a significant improvement in the BCVA and a decrease in the CMT in all RVO eyes, which were observed as early as 1 month after the injection. The peak functional and anatomical efficacy was observed at 2 months. From 3 months on, a moderate decline in the BCVA was noticed. The cumulative response rate was $41 \%$ in the $0.7 \mathrm{mg}$ group, $40 \%$ in the $0.35 \mathrm{mg}$ group, and $23 \%$ in the sham group $(\mathrm{p}=0.001)$. Although the proportion of eyes achieving at least a 15-letter improvement from the baseline BCVA was greater in the treatment groups at month $1(21 \%$ in the $0.7 \mathrm{mg}$ group vs $18 \%$ in the $0.35 \mathrm{mg}$ group vs $8 \%$ in the sham group; $\mathrm{p}=0.001$ ) and month 3 (22\% in the $0.7 \mathrm{mg}$ group vs $23 \%$ in the $0.35 \mathrm{mg}$ group vs $13 \%$ in the sham group; $\mathrm{p}=0.001$ ), this effect was no longer statistically significant at month 6 [35]. Among the patients who received two treatments with the $0.7-\mathrm{mg}$ DEX implant in the GENEVA study (12 months), BCVA improvements were similar after the first and second injections. Overall, as well as in the subgroups of study eyes diagnosed with BRVO and CRVO, the peak improvement in the mean BCVA was approximately 10 letters and occurred 60 days after each injection. At least a 15-letter improvement in BCVA from the 
baseline was observed in up to $30 \%$ of eyes in the DEX 0.7/0.7 group at visits during the masked phase of the study (the first 6 months) and in up to $32 \%$ of eyes in the DEX 0.7/0.7 group at visits during the open-label phase of the study (the second 6 months) [36].

In a retrospective report by Bezatis et al. that included eyes with BRVO, treatment with an intravitreal DEX implant resulted in a significant improvement in the median BCVA $(\mathrm{p}<0.001)$, increasing from $0.6 \log \mathrm{MAR}$ at baseline to $0.45 \log$ MAR after 6 months. The median BCVA maintained was significantly better $(p<0.001)$ compared with the baseline at each follow-up visit [27]. These findings are consistent with those from our present study. Alshahrani et al. conducted a study involving fourteen BRVO cases, and there was a statistically significant improvement in BCVA at the 3rd month. However, the improvement was not maintained at the 6-month visit [37].

In the current study, the decrease in CMT was significant in all visits compared to the initial CMT. This was consistent with the improvement in BCVA. The mean CMT maintained during the first and second visits (at months 1 and 3) was a reduced thickness of 209 and 190 microns, respectively, and there was a moderate increase during the following visits. Consistent with our findings, the GENEVA study reported that the mean CMT obtained during the first and second visits was a reduced thickness of 220 and 239 microns, respectively, while there was a moderate increase during the following weeks [35]. Bezatis et al. reported that the mean CMT maintained was significantly reduced $(\mathrm{p}<0.001)$ compared with the baseline at each follow-up visit [31]. In a study by Alshahrani et al., the mean baseline CMT was $490.86 \pm 133.94 \mu \mathrm{m}$ in eyes with BRVO. The mean CMT decreased significantly to $259.00 \pm$ $37.56 \mu \mathrm{m}$ at the 1-month visit and to $340.29 \pm$ $112.93 \mu \mathrm{m}$ at the 3-month visit $(\mathrm{p}=0.001$ and $\mathrm{p}=0.01$, respectively). However, the difference was not statistically significant at the 6-month visit $(\mathrm{p}=0.177)$ [37].

In the current study including ten CRVO cases, the outcomes were not satisfactory. We tried a second injection in seven cases $(70 \%)$, but the final BCVA was still not significantly different from the preinjection values. In the GENEVA study, the mean change in VA from the baseline in patients with CRVO was approximately +2.2 letters for retreated patients and -1.2 letters for delayed treatment patients (32). Bezatis et al. found a significant visual improvement of the mean BCVA from 0.7 logMAR at the baseline to $0.52 \log$ MAR after 6 months following the injection in eyes with CRVO. The median BCVA remained significantly better $(p<0.001)$ when compared with the baseline at each follow-up visit [31]. Alshahrani et al. observed an initial improvement in BCVA for thirteen CRVO patients following the injection at visits in the 1st and 3rd months. However, the improvement was not maintained at the 6-month visit [37]. In our study, the decrease in CMT was initially significant compared to the baseline CMT, but this was not compatible with our functional outcomes. The mean CMT decreased from the baseline $540 \pm 168$ to $496 \pm 218 \mu \mathrm{m}$ at the 12 -month visit. Bezatis et al. reported a significant decrease in CMT at all visits [31]. Alshahrani et al. also showed a significant decrease in CMT in CRVO patients at visits in the 1st, 3rd and 6th month. At 6 months, there was a statistically significant decrease in CMT from the baseline value of $656.31 \pm 220.19 \mu \mathrm{m}$ to $466.41 \pm 316.17 \mu \mathrm{m}$ $(\mathrm{p}=0.033)$ [37].

It was reported that IOP elevation and cataract are the most common complications after the intravitreal Ozurdex implant injection. In our series, IOP elevation was noted in $29.4 \%$ of the eyes with BRVO and $20 \%$ of the eyes with CRVO. Fortunately, the mean IOP levels were not different at the last visit in both groups. In the literature, IOP elevation was noted in $4 \%$ to $53 \%$ of cases with RVO after the intravitreal Ozurdex implant injection [35-39]. We operated on all of our cases in which cataract developed after the injection. Our percentage of cases that developed cataract was consistent with those reported in the literature. Cataract developed in $1.8 \%$ to $29.8 \%$ of the eyes with RVO after the intravitreal Ozurdex implant injection [31-33]. In the GENAVA (twelve months) study, 25.5\% of the cases in the dexamethasone $0.7 / 0.7 \mathrm{mg}$ group, $25.0 \%$ in the dexamethasone $0.35 / 0.7 \mathrm{mg}$ group, and $28.1 \%$ in the sham/dexamethasone $0.7 \mathrm{mg}$ group received medical treatment for IOP compared to $0 \%$ in the $0.35 \mathrm{mg} / \mathrm{no}$ implant group and the sham/no implant group. The cataract progression varied and was reported at $5.7 \%$ in the sham/no implant group, $10.5 \%$ in the sham $/ 0.7 \mathrm{mg}$ group and $29.8 \%$ in $0.7 / 0.7 \mathrm{mg}$ dexamethasone-treated patients [36].

Our study has several limitations. It was an uncontrolled study conducted in a single-center 
institutional setting and included a relatively small study population of CRVO cases. This precluded any definitive estimation of the efficacy or safety of intravitreal Ozurdex injection. The retreatment criterion of the OCT of 150 microns may be large. We could speculate that, the outcomes would be better, if our retreatment criterion was below 150 microns. Not all patients could be immediately retreated in our routine clinical setting because some insurance companies required the completion of an entire 6-month follow-up period before an additional retreatment could be assigned. The GENEVA study prohibited panretinal laser photocoagulation to solely investigate the effects of the intravitreal Ozurdex injection. We conducted a prospective study with one year of follow-up. In our current trial, additional laser photocoagulation was applied in selected cases, and this could possibly reduce the progression of the disease [40]. However, Spaide et al. reported that laser photocoagulation to peripheral areas of nonperfusion did not result in either decreased injection frequency or improved visual acuity in eyes with CRVO treated with ranibizumab [41]. CONCLUSION

Based on our monthly examinations, a significant visual improvement and reduction in CMT was noticed at all visits in the BRVO cases in one year of follow-up. In the CRVO cases, the anatomical improvement was maintained, but the visual outcome was not satisfactory. Better outcomes could be obtained, if patients were reevaluated earlier than 6 months and treated again if necessary.

\section{REFERENCES}

[1] Yau JW, Lee P, Wong TY, Best J, Jenkins A. Retinal vein occlusion: an approach to diagnosis, systemic risk factors and management. Intern Med J. 2008; 38: 904-910.

[2] Mitchell P, Smith W, Chang A. Prevalence and associations of retinal vein occlusion in Australia: the Blue Mountains Eye Study. Arch Ophthalmol. 1996; 114: 1243-1247.

[3] Sivaprasad S, Amoaku WM, Hykin P; RVO Guideline Group The Royal College of Ophthalmologists Guidelines on retinal vein occlusions: executive summary. Eye (Lond). 2015; 29: 1640.

[4] Klein R, Klein BE, Moss SE, Meuer SM. The epidemiology of retinal vein occlusion: the Beaver Dam Eye Study. Trans Am Ophthalmol Soc. 2000; 98: 133-143.

[5] Rehak J, Rehak M. Branch retinal vein occlusion: pathogenesis, visual prognosis, and treatment modalities. Curr Eye Res. 2000; 33: 111-121.

[6] Antonetti DA, Barber AJ, Khin S, Lieth E, Tarbell JM, Gardner TW. Penn State Retina Research Group. Vascular permeability in experimental diabetes is associated with reduced endothelial occludin content: vascular endothelial growth factor decreases occludin in retinal endothelial cells. Diabetes. 1998; 47: 1953-1959.

[7] Campochiaro PA, Hafiz G, Shah SM, Nguyen QD, Ying H, Do DV, Quinlan E, et al. Ranibizumab for macular edema due to retinal vein occlusions: implication of VEGF as a critical stimulator. Mol Ther. 2008; 16: 791799.

[8] SCORE Study Research Group. A randomized trial comparing the efficacy and safety of intravitreal triamcinolone with standard care to treat vision loss associated with macular edema secondary to branch retinal vein occlusion: the Standard Care vs Corticosteroid for Retinal Vein Occlusion (SCORE) Study report 6. Arch Ophthalmol. 2009; 127: 1115-1128.

[9] Campochiaro PA, Heier JS, Feiner L, Gray S, Saroj N, Rundle AC, et al.; BRAVO Investigators. Ranibizumab for macular edema following branch retinal vein occlusion: sixmonth primary end point results of a phase III study.Ophthalmology. 2010; 117: 1102-1112.

[10] Brown DM, Campochiaro PA, Singh RP, Li Z, Gray S, Saroj N, et al.; CRUISE Investigators. Ranibizumab for macular edema following central retinal vein occlusion: six-month primary end point results of a phase III study. Ophthalmology. 2010; 117: 1124-1133.

[11] Ho M, Liu DT, Lam DS, Jonas JB. Retinal Vein Occlusions, From Basics To The Latest Treatment. Retina. 2016; 36: 432-48.

[12] Panakanti TK, Chhablani J. Clinical Trials in Branch Retinal Vein Occlusion. Middle East Afr J Ophthalmol. 2016; 23: 38-43.

[13] Regnier SA, Larsen M, Bezlyak V, Allen F. Comparative efficacy and safety of approved treatments for macular oedema secondary to branch retinal vein occlusion: a network metaanalysis. BMJ Open. 2015; 5: e007527.

[14] Ozkok A, Saleh OA, Sigford DK, Heroman JW, Schaal S. THE OMAR STUDY: Comparison of Ozurdex and Triamcinolone Acetonide for Refractory Cystoid Macular Edema in Retinal Vein Occlusion. Retina. 2015; 35: 1393-400.

[15] SCORE Study Research Group. A randomized trial comparing the efficacy and safety of intravitreal triamcinolone with observation to treat vision loss associated with macular edema secondary to central retinal vein occlusion: the Standard Care vs Corticosteroid for Retinal 
Vein Occlusion (SCORE) Study report 5. Arch Ophthalmol. 2009; 127: 1101-1114.

[16] Kuppermann BD, Blumenkranz MS, Haller JA, Williams GA, Weinberg DV, Chou C, et al, Dexamethasone DDS Phase II Study Group. Randomized controlled study of an intravitreous dexamethasone drug delivery system in patients with persistent macular edema. Arch Ophthalmol. 2007; 125: 309-317.

[17] Antonetti DA, Wolpert EB, DeMaio L, Harhaj NS, Scaduto RC Jr. Hydrocortisone decreases retinal endothelial cell water and solute flux coincident with increased content and decreased phosphorylation of occludin. J Neurochem. 2002; 80: 667-677.

[18] Leopold IH. Nonsteroidal and steroidal antiinflammatory agents. In: Sears ML, Tarkkanen A, eds Surgical Pharmacology of the Eye. New York, Raven Press, 1985; 83-133.

[19] Nauck M, Karakiulakis G, Perruchoud AP, Papakonstantinou E, Roth M. Corticosteroids inhibit the expression of the vascular endothelial growth factor gene in human vascular smooth muscle cells. Eur J Pharmacol. 1998; 341: 309-315.

[20] Tennant JL. Cystoid maculopathy: 125 prostaglandins in ophthalmology. In: Emery JM, ed Current Concepts in Cataract Surgery: Selected Proceedings of the Fifth Biennial Cataract Surgical Congress. Section 3. St. Louis, MO: Mosby, 1978, 360-362.

[21] Ip MS, Gottlieb JL, Kahana A, Oden NL, Blodi BA, Fisher M, et al. Intravitreal triamcinolone for the treatment of macular edema associated with central retinal vein occlusion. Arch Ophthalmol. 2004; 122: 1131-1136.

[22] Williamson TH, O’Donnell A. Intravitreal triamcinolone acetonide for cystoid macular edema in nonischemic central retinal vein occlusion. Am J Ophthalmol. 2005; 139: 860866.

[23] Krepler K, Ergun E, Sacu S, Richter-Müksch S, Wagner J, Stur M, et al. Intravitreal triamcinolone acetonide in patients with macular oedema due to central retinal vein occlusion. Acta Ophthalmol Scand. 2005; 83: 71-75.

[24] Jonas JB, Akkoyun I, Kamppeter B, Kreissig I, Degenring RF. Intravitreal triamcinolone acetonide for treatment of central retinal vein occlusion. Eur J Ophthalmol. 2005; 15: 751758.

[25] Jonas JB, Akkoyun I, Kamppeter B, Kreissig I, Degenring RF. Branch retinal vein occlusion treated by intravitreal triamcinolone acetonide. Eye (Lond). 2005; 19: 65-71.

[26] Cekic O, Chang S, Tseng JJ, Barile GR, Weissman H, Del Priore LV, et al. Intravitreal triamcinolone treatment for macular edema associated with central retinal vein occlusion and hemiretinal vein occlusion. Retina. 2005; 25: 846-850.

[27] Chen SD, Sundaram V, Lochhead J, Patel CK. Intravitreal triamcinolone for the treatment of ischemic macular edema associated with branch retinal vein occlusion. Am J Ophthalmol. 2006; 141: 876-883.

[28] Cheng KC, Wu WC. Intravitreal triamcinolone acetonide for patients with macular edema due to branch retinal vein occlusion. Kaohsiung J Med Sci. 2006; 22: 321-330.

[29] Oh JY, Seo JH, Ahn JK, Heo JW, Chung H. Early versus late intravitreal triamcinolone acetonide for macular edema associated with branch retinal vein occlusion. Korean J Ophthalmol. 2007; 21: 18-20.

[30] Nehme A, Lobenhofer EK, Stamer WD, Edelman JL. Glucocorticoids with different chemical structures but similar glucocorticoid receptor potency regulate subsets of common and unique genes in human trabecular meshwork cells. BMC Med Genomics. 2009; 2: 58.

[31] Bezatis A, Spital G, Höhn F, Maier M, Clemens CR, Wachtlin J, et al. Functional and anatomical results after a single intravitreal Ozurdex injection in retinal vein occlusion: a 6month follow-up - the SOLO study. Acta Ophthalmol. 2013; 91: 340-347.

[32] Chan A, Leung LS, Blumenkranz MS. Critical appraisal of the clinical utility of the dexamethasone intravitreal implant (Ozurdex) for the treatment of macular edema related to branch retinal vein occlusion or central retinal vein occlusion.Clin Ophthalmol. 2011; 5: 10431049.

[33] Parodi MB, Iacono P, Cascavilla M, Zucchiatti I, Bandello F. Compassionate use of dexamethasone implant for the treatment of macular edema secondary to central retinal vein occlusion in a clinical setting. Acta Ophthalmol. 2012; 90: 322-333.

[34] The Central Vein Occlusion Study Group M Report. Evaluation of grid pattern photocoagulation for macular edema in central vein occlusion. Ophthalmology. 1995; 102: 1425-1433.

[35] Haller JA, Bandello F, Belfort R Jr, Blumenkranz MS, Gillies M, Heier J, et al.; OZURDEX GENEVA Study Group. Randomized, sham-controlled trial of dexamethasone intravitreal implant in patients with macular edema due to retinal vein occlusion.Ophthalmology. 2010; 117: 11341146.

[36] Haller JA, Bandello F, Belfort R Jr, Blumenkranz MS, Gillies M, Heier J, et al.; Ozurdex GENEVA Study Group, Li J. Dexamethasone intravitreal implant in patients 
with macular edema related to branch or central retinal vein occlusion twelve-month study results. Ophthalmology. 2011; 118: 2453-2460.

[37] Alshahrani ST, Dolz-Marco R, Gallego-Pinazo R, Diaz-Llopis M, Arevalo JF; KKESH International Collaborative Retina Study Group. Intravitreal dexamethasone implant for the treatment of refractory macular edema in retinal vascular diseases: results of the KKESH International Collaborative Retina Study Group. Retina. 2016; 36: 131-136.

[38] Mathew R, Pearce E, Muniraju R, Abdel-Hay A, Sivaprasad S. Monthly OCT monitoring of Ozurdex for macular oedema related to retinal vascular diseases:re-treatment strategy
(OCTOME Report 1). Eye (Lond). 2014; 28 : 318-326.

[39] Ferrini W, Ambresin A. Intravitreal dexamethasone implant for the treatment of macular edema after retinal vein occlusion in a clinical setting. Klin Monbl Augenheilkd. 2013; 230: 423-426.

[40] Stefansson E. The therapeutic effects of retinal laser treatment and vitrectomy. A theory based on oxygen and vascular physiology. Acta Ophthalmol Scand. 2001; 79: 435-440.

[41] Spaide RF. Prospective study of peripheral panretinal photocoagulation of areas of nonperfusion in central retinal vein occlusion. Retina. 2013; 33: 56-62

Citation: Mustafa Deger B, Nazmiye E, Huseyin G, Erdogan Y, Emre T, Ertugrul C. Intravitreal Dexamethasone Implant (Ozurdex) for Macular Edema Secondary to Retinal Vein Occlusion. International Journal of Research Studies in Medical and Health Sciences. 2017;2(3):1-10.

Copyright: (C) 2017 Mustafa Deger B, et al. This is an open-access article distributed under the terms of the Creative Commons Attribution License, which permits unrestricted use, distribution, and reproduction in any medium, provided the original author and source are credited. 